\title{
Reconstruction of the duration of autobiographical events
}

\author{
CHRISTOPHER D. B. BURT \\ University of Canterbury, Christchurch, New Zealand
}

\begin{abstract}
In two experiments, subjects estimated autobiographical event duration. Ornstein's (1969) storage-size model of duration estimation was tested in Experiment 1 by using 187 autobiographical events with an actual duration range of 3-550 days. Subjects' diaries were used to obtain information about these events, which occurred up to 20 years before the study. Contrary to the predictions of Ornstein's model, estimated duration was not proportional to event knowledge, nor was any evidence of a time-order error effect or the filled-duration illusion found. Estimated duration was reasonably accurate, even when the event could not be remembered, suggesting that subjects may have reconstructed event duration. Evidence consistent with duration reconstruction through the use of general event knowledge was found in Experiment 2: Subjects provided with general descriptions of the events used in Experiment 1 gave estimates similar to those obtained in Experiment 1 for specific events.
\end{abstract}

This study examines the recall of autobiographical event duration-as might be elicited, for example, in response to the question, "How long did you work in Canada?" Autobiographical events that extend over a reasonably long period of time have received some theoretical attention (e.g., Barsalou, 1988; Linton, 1986; Neisser, 1986; Reiser, Black, \& Kalamarides, 1986; Robinson \& Swanson, 1990) but virtually no empirical study. Theoretical discussions of extended autobiographical events have been focused mainly on their function in the organization of autobiographical memory, rather than on how information about such events is stored and retrieved from memory.

Laboratory investigations of the perception of time sug gest that an individual's indication of an interval's duration, typically referred to as a duration estimate, is proportional to the amount of information stored in memory about the interval (e.g., Ornstein's, 1969, storage-size hypothesis). Ornstein suggested that the more one can remember about an event, the longer it will be estimated to have lasted. Furthermore, he argued that information acquired during an interval will be gradually lost from memory as time passes, resulting in a tendency to underestimate event duration as retention interval increases. Burt and Kemp (1991) examined the relationship between retention interval and estimated duration by obtaining duration estimates for 36 public events that had occurred at various times in the past. No evidence was found to support Ornstein's (1969) proposed relationship between retention interval and estimated duration.

The retention interval results of Burt and Kemp (1991) contrast with the results of traditional duration estimation

Correspondence should be addressed to C. D. B. Burt, School of Behavioral Sciences, James Cook University of North Queensland, Townsville, QLD 4811, Australia. research, which suggest an effect of retention interval on estimated duration. Often referred to as time-order error, and cited as support for Ornstein's (1969) model, the effect occurs when two intervals of equal duration are presented in succession and a duration estimate is obtained for each. Generally, the second interval is estimated to have a longer duration than the first (see, e.g., Woodworth \& Schlosberg, 1954). As noted, Omstein explains this effect by assuming that the storage size of the first interval decreases in relation to that of the second interval because of the retention interval and associated memory trace decay.

Another effect consistently found in traditional duration estimation research, the filled-duration illusion, has also been used to support Ornstein's (1969) model. The filled-duration illusion consists of the finding that an interval that contains more numerous components is generally estimated to be significantly longer than an interval of similar duration containing fewer components (e.g., Buffardi, 1971; Burnside, 1971; Fraisse, 1963; Frankenhaeuser, 1959; Hall \& Jastrow, 1886; Ihle \& Wilsoncroft, 1983; Ornstein, 1969; Poynter \& Homa, 1983; Roeloefs \& Zeeman, 1951; Schiffman \& Bobko, 1977; Thomas \& Brown, 1974). Ornstein accounts for the filled-duration illusion by assuming that more components presented during an interval result in an increase in storage size.

Both the time-order error effect and the filled-duration illusion are examined in the present study as tests of Ornstein's (1969) model of duration estimation. To investigate the time-order error effect, information on extended autobiographical events that the subjects had experienced at various times in the past (up to 20 years before the study) were obtained from their diaries. Specifically, diary entries were used to obtain event descriptions and to determine event duration. Diary-keeping was not a phase of the experiment; rather, the diaries had been kept by the sub- 
jects in the course of everyday life. The 14 subjects were identified as diarists in a survey of introductory psychology students at the University of Canterbury: $58 \%$ of the 478 students sampled indicated they were or had been diarists.

The events obtained from the diaries were categorized to examine the filled-duration illusion. An event such as going on a holiday, which is basically a continuous succession of related events that are associated because they occur within a definable interval of time, was defined as a filled-duration event. An event such as "buying a raffle ticket and finding out the result," which consists of two related events separated by a succession of unrelated events, was defined as an unfilled-duration event. The distinction between a filled- and an unfilled-duration event is one of associated memory storage: a filled-duration event is characterized by many specific and associated memories, whereas an unfilled-duration event has relatively few associated memories.

There is already some evidence that time-order error is not found in duration estimates of extended autobiographical events. Although not specifically investigating duration estimation, Douglas and Blomfield (1956) reported that mothers overestimated the duration of their children's hospitalization and that this overestimation increased as the retention interval increased.

In contrast with time-order error, the filled-duration illusion does not appear to have been examined with the use of extended autobiographical events. However, there is some evidence that different types of autobiographical events result in different estimation tendencies. For example, Schneider, Griffith, Sumi, and Burcart (1978) found that 212 crime victims generally overestimated the time it took for the police to arrive at the crime scene. Similarly, Mednick and Shaffer (1963) found a tendency toward overestimation when 14 mothers were asked to estimate how long they had breast-fed one of their children. On the other hand, Pyles, Stolz, and Macfarlane (1935), who assessed mothers' estimates of gestation period and duration of labor, reported that the $\mathbf{1 5 8}$ mothers tended to underestimate the actual duration of "labor," but that they produced reasonably accurate estimates with no discernible error tendency for gestation period.

Pyles et al.'s (1935) result for gestation period estimation is particularly suggestive. It is generally recognized that this event has a duration of approximately 9 months. The mothers in the study may well have realized this and used this general knowledge to reconstruct the event's duration. Reconstruction of autobiographical event information has been demonstrated in a number of studies of event dating (e.g., Baddeley, Lewis, \& Nimmo-Smith, 1978; Burt, in press-b; Linton, 1975; Thompson, 1982; Wagenaar, 1986; White, 1982). One strategy subjects adopt when reconstructing date information is the use of general knowledge of behavior patterns and events (e.g., "I normally go skiing during the August vacation"') gained through repeated experience.

Although there is no empirical evidence of general knowledge representations for extended autobiographical events (Robinson \& Swanson, 1990), it seems reasonable that people may have general knowledge of such events. It also seems reasonable that this general knowledge may allow an event's duration to be reconstructed. Indeed, evidence of the reconstruction of public event duration through the use of general knowledge was found by Burt and Kemp (1991); subjects asked to estimate the duration of specific public events provided duration estimates similar to those of subjects who were given general descriptions of the same events. The possibility that subjects have general knowledge of extended autobiographical events and that they use this information to reconstruct duration is examined in the present study.

The reconstruction of duration information contrasts directly with Ornstein's (1969) model, in that the duration of an autobiographical event may be available in the absence of specific event knowledge. However, specific event knowledge may play a part in the reconstruction of duration information and sometimes show a relationship with estimated duration similar to that suggested by Ornstein. Such a relationship was found by Burt and Kemp (1991); event knowledge, measured on a 7-point rating scale, was positively correlated with estimated duration. Other results obtained in that study (e.g., the general tendency toward event duration underestimation) and in Burt (in press-a) suggested that this relationship was found because the events used in the study had atypically long actual durations. Event knowledge allowed subjects to adjust their reconstructed estimates in the direction of the event's actual duration, an upward adjustment or the production of a larger estimate. The effect of event knowledge was to increase estimation accuracy.

In the present study, too. event knowledge was measured with the 7-point knowledge rating scale, in an attempt to determine whether event knowledge is related to either estimated duration as predicted by Ornstein (1969) or to estimation accuracy. Of course these analyses rely on the assumption that the knowledge rating scale accurately reflects event knowledge. Support for this assumption was found by Burt and Kemp (1991), who found that knowledge scale ratings for public events were positively correlated with performance on a true/false recognition task.

\section{EXPERIMENT 1}

\section{Method}

Subjects. Fourteen subjects (diarists)-11 females between 18 and 36 years of age ( $M=22.1$ years) and 3 males who were 19 or 20-volunteered to participate in the study in response to an offer of a restaurant meal for doing so. The subjects were required to provide the experimenter with diary material that they had kept; diary-keeping was not a phase of the experiment. In total, 48 years of diary records were submitted for examination. The submitted diaries covered years between 1963 and 1987, and the number of diaries submitted by each subject ranged from 1 to 9 .

Event selection and interview schedule formulation. Each subject's diary records were examined for suitable duration events by the author. The defining characteristic of a duration event is that it must have lasted for more than 1 day. The two types of duration 
events defined above were searched for (e.g., filled- and unfilledduration events).

In total, information on 187 duration events was obtained. Actual event duration was obtained from the diaries and ranged from 3 to 550 days. The days on which the event began and ended were both counted as whole days. One hundred and fourteen events were categorized as filled-duration, the remaining 73 being unfilled duration. Table 2 shows the 11 types of events within the filledduration category and the 12 types of events within the unfilledduration category

The details of duration events obtained from the subjects' diaries were formulated into event descriptions. The event description for a filled-duration event required only a single statement (e.g., "You and Paul went on a holiday to Australia"). For an unfilled-duration event, the event description described the two associated events (e.g. "You sent an order to Smith's for a Blackheart stamp. Some time later the stamp arrived."). A duration question relating to the event description was formulated. In the above filled-duration event example, it would be "How long were you and Paul in Australia?"

Procedure. The event description and duration question were read to the subject. The subject then gave a knowledge rating for the event and answered the duration question. Duration estimates were made in terms of days, weeks, months, or some combination of these. The subjects were instructed to count the day on which the event began and the day on which the event ended as two complete days.

Response choices on the 7-point knowledge rating scale were defined as follows: (1) I cannot remember this event; (2) I can just barely remember it; (3) I remember it but not so well; (4) I remember it fairly well; (5) I remember it very well; (6) I remember it almost perfectly; and (7) I remember it perfectly.

The interview procedure was explained to the subject at the beginning of the interview. It was noted that the questions would be presented in a random (nontemporal) sequence and that there was no time limit for answering. The subjects' responses were recorded in their interview schedules by the author. Interviews were conducted at the University of Canterbury between the 14th of October, 1986, and the 29th of April, 1988.

\section{Results}

Table 1 shows the median actual duration, the median estimated duration, the median absolute error, the median percentage error, and the correlation between actual and estimated duration for each subject and overall. (Absolute error was calculated by subtracting actual event duration from estimated event duration and ignoring the sign of the error. In the case of percentage error, absolute error was divided by actual event duration.) Inspection of the within-subject correlations between actual and estimated event duration shown in Table 1 suggests that all the subjects were reasonably capable of estimating the durations of their events, a result reflected in the overall correlation. Further evidence of the subjects' ability to estimate duration is seen in their median absolute and percentage error scores. The absolute error medians indicate that estimated duration was often quite accurate, close to actual event duration. The percentage error medians indicate that this estimation ability was reasonably similar across the subjects, despite large retention interval differences.

Median retention intervals are shown in Table 1, as is the median signed error for each subject and overall. (Retention interval equals the time between the beginning of an event and the interview date. Signed error was calculated by subtracting actual event duration from estimated event duration.) Inspection of the overall median signed error ( 0 days) indicates that there was no overall tendency to either over- or underestimate event duration, although there is some indication of both tendencies at the within-subject level. The within-subject median signed error differences are, however, not what might be expected if the subject's estimates were based on memory storage. That is, according to Ornstein (1969), the subjects with the longer retention intervals might have been expected to have negative median signed errors-that is, to have generally underestimated event duration. This proposition, of course, relies on the assumption that memory storage decreases as retention interval increases.

Examination of the correlation between retention interval and knowledge ratings, using only the remembered events ( 17 events were given a rating of 1 , indicating that

Table 1

Median Retention Interval, Actual Duration, Estimated Duration, Absolute, Percentage, and Signed Error, and the Correlation Between Actual and Estimated Duration, for Each Subject in Experiment 1

\begin{tabular}{|c|c|c|c|c|c|c|c|c|}
\hline Subject & $\begin{array}{l}\text { Median } \\
\text { Retention } \\
\text { Interval } \\
\text { (Days) }\end{array}$ & $\begin{array}{l}\text { Median } \\
\text { Actual } \\
\text { Duration } \\
\text { (Days) }\end{array}$ & $\begin{array}{l}\text { Median } \\
\text { Estimated } \\
\text { Duration } \\
\text { (Days) }\end{array}$ & $\begin{array}{c}\text { Median } \\
\text { Percentage } \\
\text { Error } \\
\text { (Days) }\end{array}$ & $\begin{array}{c}\text { Median } \\
\text { Absolute } \\
\text { Error } \\
\text { (Days) } \\
\end{array}$ & $\begin{array}{l}\text { Median } \\
\text { Signed } \\
\text { Error } \\
\text { (Days) } \\
\end{array}$ & $\begin{array}{l}\text { Spearman Rank } \\
\text { Correlation } \\
\text { Between Actual } \\
\text { and Estimated } \\
\text { Duration }\end{array}$ & $\begin{array}{l}\text { Number } \\
\text { of Events }\end{array}$ \\
\hline 1 & 380.0 & 4 & 4 & 6.7 & 1 & 0 & $.90^{*}$ & 7 \\
\hline 2 & 405.5 & 4 & 5 & 18.6 & 2 & -1 & .74 & 6 \\
\hline 3 & 596.0 & 36 & 60 & 25.0 & 5 & 4 & $.98 \dagger$ & 7 \\
\hline 4 & 608.8 & 4 & 5 & 25.0 & 1 & 1 & .81 & 5 \\
\hline 5 & 916.5 & 7 & 11 & 32.3 & 5 & 2.5 & $.77 \dagger$ & 16 \\
\hline 6 & $1,117.9$ & 22 & 14 & 44.4 & 7 & 0 & $.87 \dagger$ & 26 \\
\hline 7 & $1,182.9$ & 5 & 4 & 33.3 & 2 & -1 & $.81^{*}$ & 9 \\
\hline 8 & $1,193.1$ & 5.5 & 6 & 28.1 & 2.5 & -1 & .63 & 4 \\
\hline 9 & $1,253.7$ & 26 & 14 & 25.0 & 6 & -1 & .80 & 5 \\
\hline 10 & $1,263.9$ & 8 & 5 & 40.0 & 7 & -2 & .60 & 5 \\
\hline 11 & $1,403.0$ & 9 & 14 & 55.2 & 9 & 1 & $.69+$ & 49 \\
\hline 12 & $1,902.7$ & 16 & 21 & 40.0 & 4 & 1 & $.86 \dagger$ & 17 \\
\hline 13 & $4,364.3$ & 9 & 10 & 28.4 & 3.5 & .5 & $.73 \dagger$ & 20 \\
\hline 14 & $7,273.7$ & 10 & 7 & 24.3 & 1.5 & 0 & $.78^{*}$ & 26 \\
\hline Overall & $1,359.3$ & 9 & 10 & 33.3 & 4.0 & 0 & $.79 \dagger$ & 187 \\
\hline
\end{tabular}

Note-Significant levels are for two-tailed tests.

${ }^{*} p<.01 . \quad+p<.001$.


they were not remembered by the subject), indicated that, indeed, memory storage might have decreased as retention interval increased $(\rho=-.17, p<.05)$. Unfortunately, retention interval and actual duration were also correlated $(\rho=.14, p<.05)$, indicating that an examination of the relationship between retention interval and estimated duration would not be valid. However, removal of the data of Subject 14, the subject with the longest median retention interval, from the analysis resulted in the correlation between retention interval and actual duration becoming nonsignificant $(\rho=.10 \mathrm{n} . \mathrm{s}$.).

The data from Subject 14 were therefore excluded from the retention interval analysis. Correlating estimated duration and retention interval indicated no significant relationship between the variables $(\rho=.10$, n.s.). Similarly, no significant relationship was found between signed error and retention interval $(\rho=.01$, n.s. $)$. The obtained correlations show no evidence of a time-order error effect; memory trace decay associated with increasing retention interval did not produce underestimation of event duration. However, there was an effect of retention interval on estimation accuracy, indicated by the small, yet significant $(p<.05)$, correlation obtained between retention interval and percentage error $(\rho=.18)$. Apparently, estimation accuracy decreased as retention interval increased, but the error made was just as likely to be an overestimation as an underestimation.

The relationship between event memory and estimated duration was further examined by correlating knowledge ratings and estimated duration. (Examination of the knowledge ratings indicated they were reasonably well distributed: $17,21,37,53,35,19$, and 5 events were given knowledge ratings of $1,2,3,4,5,6$, and 7 , respectively.) Calculating the correlation by using only the remembered events produced a nonsignificant result $(\rho=.06)$. Thus, estimated duration was not proportional to event memory as measured by the knowledge ratings. The possibility that a relationship between knowledge ratings and estimated duration was not found because the better remembered events were actually shorter in duration and the less well remembered events actually longer can be discounted, because the correlation between the knowledge ratings and actual event duration $(\rho=.01)$ was not significant.

As has been noted in the preceding analyses, only the remembered events were used. To examine the estimates of the "forgotten" events, and as a further test of Ornstein's (1969) model, the events were divided into three groups on the basis of event knowledge. Group 1 contained events given a rating of 5-7 on the knowledge scale $(N=59)$, Group 2 events given a rating of 2-4 $(N=$ $111)$, and Group 3 events given a rating of $1(N=17)$. Estimated event duration was compared between the groups by using analysis of covariance with actual event duration as the covariate. Again, no indication that event knowledge was positively related to estimated event duration was found $[F(3,184)=2.458$, n.s. $]$. In particular, the finding that the duration estimates of the forgotten events (Group 3) were not significantly different from the remembered event estimates (Groups 1 and 2) argues against an effect of event knowledge on the length of an event's estimated duration.

Further analysis was performed to determine the effect of event characteristics (e.g., filled- or unfilled-duration) on estimated duration. Table 2 shows the median actual duration, median estimated duration, median signed and percentage error, and mean knowledge rating for each type of event within the filled-and unfilled-duration event categories. Comparison of the knowledge ratings of the remembered filled-and unfilled-duration events (mean knowledge ratings of 4.24 and 3.73 , respectively) supports the suggestion that the two types of events varied in associated memory storage $[F(1,168)=6.570, p<$ $.01]$. However, no evidence was found to suggest that the filled-/unfilled-duration event memory storage difference affected estimated duration. Analysis of covariance, with actual event duration as the covariate, produced a nonsignificant result when the signed error was compared between the filled-and unfilled-duration events $[F(2,167)=$ 0.721 , n.s.] and when estimated duration was similarly compared $[F(2,167)=0.128$, n.s. $]$.

In contrast to the predictions of Ornstein's (1969) model, the durations of the filled events were not overestimated. Indeed, inspection of the overall median signed and percentage errors shown in Table 2 indicates the opposite-there was a slight tendency for the durations of unfilled events to be overestimated and for more error to be associated with the unfilled event estimates than with the filled event estimates. Further evidence of the latter was found when percentage error was compared, in an analysis of covariance with actual duration as the covariate, between the filled-and unfilled-duration events $[F(2,167)$ $=4.904, p<.05$ ].

The preceding analysis yielded no evidence of Ornstein's (1969) predicted positive relationship between event knowledge and estimated duration. However, there was some indication of an effect of event knowledge on estimation accuracy. It is probably fair to assume that both the positive correlation between retention interval and percentage error and the significant percentage error difference between the filled and unfilled events resulted because of event knowledge differences. Further evidence of this was found when knowledge ratings and percentage error were correlated by using only the remembered events $(\rho=-.26, p<.01)$. However, knowledge of an event appears not to be a necessary aspect for estimation accuracy, as is indicated by the result obtained when analysis of covariance was used to compare percentage error across the three event knowledge groups defined above $[F(3,183)=0.439$, n.s. $]$.

\section{Discussion}

Despite extensive analysis, no support was found for Ornstein's (1969) suggestion that the size of a duration estimate is directly proportional to the amount of information stored in memory from the interval that is being estimated. In contrast with the results of traditional dura- 
Table 2

Median Actual Duration, Estimated Duration, Percentage and Signed Error, and Mean Knowledge Rating for Each Type of Event Within the Filled- and Unfilled-Duration Event Categories Used in Experiment 1

\begin{tabular}{|c|c|c|c|c|c|c|}
\hline Event Type and Experiment 2 Events & $N$ & $\begin{array}{c}\text { Median } \\
\text { Actual } \\
\text { Duration } \\
\text { (Days) }\end{array}$ & $\begin{array}{c}\text { Median } \\
\text { Estimate } \\
\text { Duration } \\
\text { (Days) }\end{array}$ & $\begin{array}{l}\text { Median } \\
\text { Percent- } \\
\text { age Error } \\
\text { (Days) }\end{array}$ & $\begin{array}{l}\text { Median } \\
\text { Signed } \\
\text { Error } \\
\text { (Days) }\end{array}$ & $\begin{array}{c}\text { Mean } \\
\text { Knowledge } \\
\text { Rating }\end{array}$ \\
\hline \multicolumn{7}{|c|}{ Filled-Duration Events } \\
\hline Friend/s come to stay* & 8 & 3.5 & 4.0 & 35.4 & -1.0 & 2.6 \\
\hline Official trip* & 16 & 3.5 & 4.0 & 0.0 & 0.0 & 4.4 \\
\hline Holiday* & 49 & 7.0 & 10.0 & 25.0 & 0.0 & 4.0 \\
\hline Acted in play & 2 & 8.0 & 14.0 & 75.0 & 3.0 & 2.5 \\
\hline Hospitalized* & 5 & 11.0 & 5.0 & 40.0 & -5.0 & 3.8 \\
\hline Vacation job* & 8 & 17.5 & 15.0 & 37.3 & 6.0 & 5.0 \\
\hline Medical treatment & 4 & 25.5 & 51.0 & 101.6 & 11.0 & 5.2 \\
\hline Have a pet (e.g., frog) & 5 & 30.0 & 30.0 & 25.4 & 0.0 & 4.0 \\
\hline Take course (e.g., ballroom dancing)* & 10 & 47.5 & 56.0 & 25.5 & 9.0 & 4.3 \\
\hline Construct something (e.g., model boat)* & 6 & 55.5 & 14.0 & 69.2 & -18.5 & 2.6 \\
\hline Relationship & 1 & 170.0 & 150.0 & 11.8 & -20.0 & 6.0 \\
\hline Overall & 114 & 7.0 & 7.0 & 28.6 & 0.0 & 4.2 \\
\hline \multicolumn{7}{|c|}{ Unfilled-Duration Events } \\
\hline Have something done-have it redone & 3 & 5.0 & 3.0 & 40.0 & 0.0 & 4.3 \\
\hline Receive invitation-attend* & 13 & 7.0 & 14.0 & 55.2 & 4.0 & 3.5 \\
\hline Buy something-pick it up* & 15 & 9.0 & 9.0 & 46.2 & .5 & 2.9 \\
\hline Friend/relative goes away-returns & 7 & 12.0 & 10.0 & 26.8 & -2.0 & 3.1 \\
\hline Sit test-get result* & 3 & 12.0 & 14.0 & 11.1 & 1.0 & 3.6 \\
\hline Lose something-find $\mathrm{it}^{*}$ & 8 & 13.0 & 21.0 & 85.4 & 2.0 & 3.3 \\
\hline See a movie-see it again & 2 & 14.0 & 5.5 & 52.7 & -8.5 & 4.5 \\
\hline Apply for position-hear result* & 12 & 14.5 & 20.5 & 58.6 & 3.0 & 3.8 \\
\hline Order something by mail-receive it* & 3 & 38.0 & 30.0 & 25.0 & -3.5 & 2.6 \\
\hline Photograph taken-view it* & 3 & 58.0 & 60.0 & 56.5 & 2.0 & 4.0 \\
\hline Buy concert ticket-attend* & 3 & 86.0 & 42.0 & 52.8 & 4.0 & 3.6 \\
\hline Finish course-start related course & 1 & 91.0 & 7.0 & 92.3 & -84.0 & 1.0 \\
\hline Overall & 73 & 14.0 & 14.0 & 47.5 & 1.0 & 3.7 \\
\hline
\end{tabular}

Note-Table values are actual values rather than median when there is only one event in the cell. *Event type is used in Experiment 2.

tion estimation research, no evidence of the filled-duration illusion or a time-order error effect was found. Overall, the subjects were reasonably accurate at estimating the duration of events that they had experienced, regardless of the time since the event's occurrence, the nature of the event (e.g., filled- or unfilled-duration), or whether they could not actually remember the event.

It seems unlikely that the subjects simply guessed the durations, particularly considering the observed effect of event knowledge on percentage error. It also seems unlikely that the subjects generally remembered event duration, although for some events actual duration may have been remembered, since estimates were exactly correct for 30 of the events. On the other hand, 2 of the events for which duration was exactly estimated were stated as not remembered by the respective subjects. Furthermore, overall, the duration estimates of the events that were not remembered were as accurate as the remembered event estimates. One explanation that can account for both the effect of event knowledge on estimation accuracy and the subject's ability to provide reasonably accurate estimates for forgotten events is that the subjects used a reconstructive strategy to estimate event duration.

Reconstructing event duration may involve the use of (1) general event knowledge already stored in memory,
(2) information provided in the event description, and (3) memory of the event. General knowledge of duration events may be gained from repeated experience. Over time, individuals probably experience many similar, although distinguishable, duration events. As more instances of a specific type of duration event are encountered, an individual may develop a general knowledge representation of that type of event. Time information, such as event duration, may be part of this general event knowledge. Subjects in Experiment 1 may have categorized a described event as a particular type and accessed their general knowledge for that type of event. This strategy would provide what might be termed an event type's typical duration, which could then be used as a duration estimate response.

Memory of the event for which a duration estimate was requested may have suggested to the subject that the event had an atypical duration and that an adjustment to the reconstructed estimate was required. For example, the subject might have regularly gone on a tramping holiday in a national park for between 5 and 7 days-an event type with a typical duration of approximately 6 days. The prompt to recall the actual duration of one of these tramping holidays (event description) might have contained sufficient information for the subject to recall the specific tramp in question. As part of this memory, the subject 
might have remembered heavy rain and flooded rivers, resulting in an extended stay in the bush. This recalled information might have prompted the subject to increase the size of the estimate. That is, rather than give an estimate of 6 days-the typical duration of the type of eventthe subject might have given an estimate of, say, 9 days. If the subject's memory of the event was correct, the adjustment to the reconstructed estimate would probably have increased estimation accuracy. Hence, there would have been a positive effect of event memory on estimation accuracy.

Alternatively, reconstruction of event duration might have involved the use of specific events. That is, rather than use general knowledge of an event type to reconstruct event duration, the subjects might have based their estimates on the duration of a specific category member that they recalled. For example, if asked to estimate the duration of a specific tramping holiday that occurred 15 years ago, the subject might have recalled the duration of a recent tramping holiday and used this duration information as a basis for the estimate. Event knowledge could also be used in the manner described above to adjust an estimate generated with this strategy.

Both reconstructive strategies suggest testable hypotheses. If the duration estimates obtained in Experiment 1 were reconstructed through the use of general knowledge of types of events, these estimates should be similar to estimates obtained from subjects given only general descriptions of the same events. In contrast, reconstructing duration for a general event description through the use of available specific event information might be expected to produce somewhat different estimates from those obtained in Experiment 1. The latter hypothesis is based on the assumption that different subjects will use different specific events and that different specific events will almost certainly vary in actual event duration. This reasoning also suggests that estimates reconstructed for any specific type of event with the use of the specific event availability strategy might vary considerably between subjects. In contrast, estimates reconstructed for any specific type of event with the use of general event knowledge might be expected to be reasonably similar across subjects. These hypotheses are tested in Experiment 2.

\section{EXPERIMENT 2}

\footnotetext{
Method

Questionnaires. Fifteen of the 23 event types shown in Table 2 were selected (the selected event types are indicated by an asterisk in Table 2). Selection was based partly on the number of events within the category that were used in Experiment 1, and partly to ensure approximately the same number of filled- and unfilledduration event types. The former criterion was used so that the median duration estimates shown in Table 2 could be compared with medians obtained in Experiment 2. The actual event descriptions are shown in Table 3.

Two questionnaires were constructed: the duration estimation process questionnaire and the specific event recall questionnaire. Questions relating to the subjects' age and sex were on the cover page of each questionnaire, along with instructions. Each contained the
}

15 event descriptions assigned to matched positions, and each asked for an estimate of the type of event's duration. Duration estimates were to be made in terms of days, weeks, months, or some combination of these.

The duration estimation process questionnaire contained a question that listed four possible strategies that the subject could have adopted when providing duration estimates: (1) "I counted the number of separate components or subevents of this type of event and based my duration estimate on this count." (2) "My duration estimate is based on general knowledge and logical characteristics of this type of event." (3) "My duration estimate is a wild guess that is in no way based on any knowledge of this type of event." (4) "I remembered the duration of a spocific instance of the type of event described in the event description; I then used this duration information as the basis for my duration estimate." Space was also provided for the subject to detail another strategy if those listed were not adequate.

The specific event recall questionnaire contained a specific event question: Subjects were asked whether they could recall a specific event of the type described in the event description, and if so, to describe it briefly.

Subjects. The subjects completed either the duration estimation process or specific event recall questionnaire. Fourteen males and 16 females, with ages in the range of 16-37 years, from the introductory psychology course at the University of Canterbury completed the former questionnaire. Eleven male and 12 female subjects from the same course, with ages in the range of 17-50 years, completed the specific event recall questionnaire.

Procedure. Both questionnaires were distributed to the subjects during class time. The subjects were instructed to read the instructions printed on the cover, complete all the questions, and return the questionnaires during the next day's class. All subjects completed their questionnaires in July 1990.

\section{Results and Discussion}

Table 3 shows the median estimated duration calculated for each event type for both questionnaires. Both groups of median estimates were compared with the appropriate median estimates obtained in Experiment 1 (those shown in Table 2). Neither comparison produced a significant difference $[t(14)=-.72$, n.s., and $t(14)=-1.031$, n.s., for the duration estimation process and specific event recall groups, respectively]. Similar results were obtained when the two groups of median estimates obtained in Experiment 2 were compared with the median actual durations from Experiment $1[t(14)=-1.122$, n.s., and $t(14)$ $=1.299$, n.s., for the duration estimation process and specific event recall groups, respectively]. The similarity between the estimates based on specific event descriptions (Experiment 1) and on general event descriptions (Experiment 2) suggests that the estimates made in Experiment 1 and in Experiment 2 might have been reconstructed with the use of general event knowledge.

A significant correlation $(p<.001)$ was obtained between the duration estimation process and specific event recall median estimates $(\rho=.90)$. The high correlation suggests that the two groups gave similar duration estimates. Inspection of Table 3 supports this suggestion; the two groups produced identical median estimates for four of the events. Further support for this suggestion was found when the two groups of median estimates were compared $[t(14)=-1.767, \mathrm{n} . \mathrm{s}$.]. These results also argue for reconstruction through the use of general event knowl- 
Table 3

Median Estimated Duration Obtained With the Specific Event Recall Questionnaire and the Duration Estimation Process Questionnaire for Each Event Type Used in Experiment 2

\begin{tabular}{|c|c|c|}
\hline Event Type & $\begin{array}{c}\text { Specific Event } \\
\text { Recall: } \\
\text { Median Duration } \\
\text { Estimate (Days) }\end{array}$ & $\begin{array}{c}\text { Duration Estimation } \\
\text { Process: } \\
\text { Median Duration } \\
\text { Estimate (Days) } \\
\end{array}$ \\
\hline A friend comes and stays with you & 4 & 3 \\
\hline You work in a holiday job & 57 & 60 \\
\hline You go on a holiday & 14 & 14 \\
\hline You go on an official trip (e.g., school camp) & 4 & 4.5 \\
\hline You take a course in something (e.g., ballroom dancing) & 56 & 56 \\
\hline You are hospitalized for some reason & 4 & 7 \\
\hline You construct something (e.g., build a model boat) & 3 & 14 \\
\hline You receive an invitation and later attend the function & 21 & 17.5 \\
\hline Your photograph is taken and later you see it & 10 & 14 \\
\hline You order something by mail and later it arrives & 18 & 21 \\
\hline You lose something and later find it & 3 & 2 \\
\hline You sit a test and later get the results & 21 & 21 \\
\hline You apply for a job and later hear the result & 7 & 14 \\
\hline You buy a concert ticket and later attend the concert & 14 & 14 \\
\hline You buy something and later pick it up & 3 & 2 \\
\hline
\end{tabular}

edge. The two groups of estimates might be expected to be somewhat different if the subjects had adopted a specific event availability strategy, simply because the two groups would have reconstructed duration by using different events.

However, a reasonable proportion (44.8\%) of the estimates obtained with the duration estimation process questionnaire were stated to be based on specific event recall. Of the remaining estimates, $28.4 \%$ were stated to be based on general event knowledge, $9.3 \%$ guesses, $15.8 \%$ based on an event component count, and $1.7 \%$ "other." These results suggest that the reconstruction of event duration may sometimes involve specific event availability. That is, subjects may base their reconstruction of event duration on the duration of a specific event that they can remember.

To further examine the possibility that some estimates were based on specific event availability, between-subject estimation variance was compared across the 15 events for the estimates stated to be based on specific events and those stated to be based on general event knowledge. No significant difference $[t(14)=1.802$, n.s.] was found. This result is not consistent with reconstruction through the use of specific event availability, and it suggests that subjects who stated that they based their estimates on specific events may not have actually done so. As noted earlier, the use of specific events would probably lead to an increase in estimation variance because of the variable nature of actual event duration.

Inspection of the subjects' estimates supported the suggestion that specific events may not have been used. For any event type, a number of the estimates stated to be based on specific events were identical. For example, 9 of the 15 estimates stated to be based on specific events for event type ("You sit a test and later get the results") were 21 days, and 7 of the 12 estimates stated to be based on a specific event for event type ("You apply for a job and later hear the result") were 14 days. It seems highly unlikely that so many specific events experienced by different subjects would have identical durations. These estimates display characteristics which suggest that they are based on general knowledge of the type of event's typical duration.

Categorization of one's experiences perhaps reflects a certain amount of general event knowledge. Ability to categorize experiences was demonstrated by the subjects who completed the specific event recall questionnaire. A reasonable number of specific events $(M=11.6)$ were described by each subject. This result also indicates that these subjects had experienced duration events similar to those used in Experiment 1. This appears to be true for both the filled- and the unfilled-duration events, as is indicated by the proportion of specific events recalled in response to each type of event description $(48.0 \%$ and $52.0 \%$, respectively).

\section{GENERAL DISCUSSION}

No support was found for Ornstein's (1969) model in Experiment 1. On the contrary, evidence was found which suggests that subjects can provide a reasonably accurate estimate of the duration of an extended autobiographical event even if they cannot actually remember the event. Experiment 2 suggests that individuals may use general knowledge of extended autobiographical events to reconstruct duration information and that this type of information retrieval strategy might have been used in Experiment 1 to provide estimates for both remembered and forgotten events. This suggestion of how the duration of autobiographical events is estimated is consistent with the results obtained by Burt and Kemp (1991) for the estimation of public events.

The reconstructive model of duration estimation is, of course, based on the assumption that duration informa- 
tion is encoded in memory at the time of an event's occurrence. Thus, there is a possibility that one actually remembers an event's duration. For example, if someone were to ask a few days after one arrived home, "How long were you on holiday?" one would probably be able to remember. However, as the time since the event's occurrence (retention interval) increases, the ability to recall actual event duration probably diminishes, and, if one is required to supply such information, one probably generates a response on the basis of general knowledge of the type of event in question. Hence, reconstruction of duration information is perhaps more likely than actual recall of event duration if the event in question has occurred in the remote past.

Retention interval may also influence the reconstruction of duration information through its effect on event memory. In Experiment 1, event memory was positively related to estimation accuracy; the durations of better remembered events were estimated more accurately. This was interpreted to indicate that an estimate reconstructed on the basis of general knowledge might be adjusted (e.g., a shorter or longer estimate given) if the subject recalled some information about the event which suggested that its duration would have been shorter or longer. This type of duration estimate adjustment is perhaps likely to diminish as retention interval increases, simply because the individual may have greater difficulty in recalling information about the event as the time since its occurrence increases. Hence, the estimated duration of an extended autobiographical event may be affected by memory storage, but it is probably not proportional to memory storage as Ornstein (1969) suggested.

Systematic estimation errors (e.g., over- or underestimation) may occur if event knowledge is not available or not sufficient to allow an adjustment to a reconstructed duration estimate and if the event in question has an atypical actual duration. This reasoning may account for the overall estimation tendencies found in other studies. For example, the general tendency toward event duration overestimation found by Douglas and Blomfield (1956), Mednick and Shaffer (1963), and Schneider et al. (1978) may have resulted because the actual durations of the majority of the events used in these studies were atypically short. Therefore, such tendencies are not inconsistent with duration estimate reconstruction through the use of general knowledge of events.

Overall, the strategy that an individual adopts to provide a duration estimate for an extended autobiographical event is probably mediated by the time since the event's occurrence. If the event has occurred only a couple of days previously, the individual may actually remember how long it lasted. At longer retention intervals, a duration estimate for an extended autobiographical event is probably a reconstruction based on general knowledge of the type of event in question. Furthermore, eventknowledge-based adjustments to a reconstructed duration estimate, which may influence estimation accuracy, probably diminish as retention interval increases, because it becomes more difficult to recall event information.

\section{REFERENCES}

Baddeley, A. D., LewTs, V., « Nimmo-Smith, I. (1978). When did you last ... ? In M. M. Gruneberg \& R. N. Sykes (Eds.), Practical aspects of memory (pp. 73-83). London: Academic Press.

BARSALOU, L. W. (1988). The content and organization of autobiographical memories. In U. Neisser \& E. Winograd (Eds.), Remembering reconsidered: Ecological and traditional approaches to memory (pp. 193-243). Cambridge: Cambridge University Press

BUFFARDI, L. (1971). Factors affecting the filled-duration illusion in the auditory, tactual, and visual modalities. Perception \& Psychophysics, 10, 292-294.

BURNSIDE, W. (1971). Judgment of short time intervals while performing mathematical tasks. Perception \& Psychophysics, 9, 404-406.

BURT, C. D. B. (in press-a). The effect of actual event duration and event memory on the reconstruction of duration information. Applied Cognitive Psychology.

BURT, C. D. B. (in press-b). Retrieval characteristics of autobiographical memories: Event and date information. Applied Cognitive Psychology.

BURT, C. D. B., Kemp, S. (1991). Retrospective duration estimation of public events. Memory \& Cognition, 19, 252-262.

Douglas, J. W. B., BLomfielo, J. M. (1956). The reliability of longizudinal surveys. Millbank Memorial Fund Quarerly, 34, 227-252.

Fraisse, P. (1963). The psychology of time. New York: Harper \& Row. Frankenharuser, M. (1959). Estimation of time: An experimental study. Stockholm: Almquist \& Wiksell.

HALL, G. S., JASTROW, J. (1886). Snudies of thythm. Mind, 11, 55-62. IHLE, R. G., WILSONCROFT, W. E. (1983). The filled-duration illusion: Limits of duration of interval and auditory fillers. Perceptual \& Motor Skills, 56, 655-660.

LinToN, M. (1975). Memory for real world events. In D. A. Norman \& D. E. Rumelhart (Eds.), Explorations in cognition (pp. 376-404). San Francisco: W. H. Freeman.

LiNTON, M. (1986). Ways of searching and the contents of memory. In D. C. Rubin (Ed.), Autobiographical memory (pp. 50-70). Cambridge: Cambridge University Press.

Mednick, S. A., ShAFFer, J. B. P. (1963). Mothers' retrospective reports in child-rearing research. American Joumal of Orthopsychiatry, 33, $457-461$.

NEISSER, U. (1986). Nested structure in autobiographical memory. In D. C. Rubin (Ed.), Autobiographical memory (pp. 71-81). Cambridge: Cambridge University Press.

ORNSTEIN, R. E. (1969). On the experience of time. Harmondsworth, U.K.: Penguin.

Poynter, W. D., Homa, D. (1983). Duration judgment and the experience of change. Perception \& Psychophysics, 33, 548-560.

Pyles, M. K., Stolz, H. R., a Macfarlang, J. W. (1935). The accuracy of mothers' reports on birth and developmental data. Child Development, 6, 165-176.

Reiser, B. J., Black, J. B., Kalamarides, P. (1986). Strategic memory search processes. In D. C. Rubin (Ed.), Autobiographical memory (pp. 100-121). Cambridge: Cambridge University Press.

Robinson, J. A., SWanson, K. L. (1990). Autobiographical memory: The next phase. Applied Cognitive Psychology, 4, 321-335.

Rozloefs, C. O., Zeeman, W. (1951). Influence of different sequences of optical stimuli on the estimation of duration of a given interval of time. Acta Psychologica, 8, 89-128.

SChiffMan, H. R., BoBko, D. J. (1977). The role of number and familiarity of stimuli in the perception of brief temporal intervals. American Joumal of Psychology, 90, 85-93.

SChneider, A. L., Griffith, W. R., Sumi, D. H., \& Burcart, J. M. (1978). Portland forward records check of crime victims. Washington, DC: U. S. Department of Justice. 
Thomas, E. A. C., \& Brown, I., JR. (1974). Time estimated and the filled-duration illusion. Perception \& Psychophysics, 16, 449-458.

Thompson, C. P. (1982). Memory for unique personal events: The roommate study. Memory \& Cognition, 10, 324-332.

WAGENAAR, W. A. (1986). My memory: A study of autobiographical memory over six years. Cognitive Psychology, 18, 225-252.

WHITE, R. T. (1982). Memory for personal events. Human Learning, 1, 177-183.
WOODWORTH, R. S., SCHLOSBERG, H. (1954). Experimental psychology. New York: Holt.

(Manuscript received October 15, 1990 ; revision accepted for publication September 6, 1991.)

\title{
Notices and Announcements
}

\author{
Workshop \\ Memory Strategies: Theory and Application \\ University of Trieste \\ November 6-7, 1992
}

\section{CALL FOR PAPERS}

A workshop on memory strategies will be held at the University of Trieste, November 6-7, 1992. The workshop is aimed at analyzing the role of cognitive strategies in storage and retrieval processes, and will focus on the main questions of the current debate: What is a "strategy"? What are the roles of attentional processes, metacognition factors, and intentions in adopting a memory strategy? What are the conditions that lead to the use of a specific strategy? What are the implications for a general model of the mind's architecture?

Invited speakers will include Graham Hitch, Asher Koriat, Michael Pressley, and Wolfgang Schneider.

Contributions addressing theoretical, experimental, and applied aspects of the topic are welcome. The deadline for sending proposals is April 10, 1992. All proposals, typed on a single sheet of paper, should consist of a title, a 250-word abstract, and the name, affiliation, and full postal address of each participant. Submissions should be forwarded in duplicate to Maria Antonella Brandimonte, Dipartimento di Psicologia, Università di Trieste, via dell'Università 7, 34123 Trieste, Italy.

The workshop program will include oral presentations, guest speakers, and poster presentations. Equal status will be given to poster and paper presentations. The scientific committee will have final responsibility for the allocation of each paper to either an oral or a poster discussion session.

The registration fee is 80,000 Italian Liras for participants and 40,000 Italian Liras for students. Payment of the fee should be addressed to PSY.CO 41554/0 Cassa di Risparmio di Trieste, Sede Centrale, Via Cassa di Risparmio 10, 34100 Trieste. 